\title{
Assessing Basic Needs in Frail Older Persons Calls for Aesthetic Nursing Skills - An Ethnographic Approach
}

\author{
Mette Geil Kollerup ${ }^{1 *}$ and Sanne Angel $^{2}$ \\ ${ }^{1}$ Department of Nursing, Aalborg Municipality Denmark \\ ${ }^{2}$ Department of Nursing, Institute of Public Health, Aarhus University, Denmark
}

Received: July 02, 2015; Accepted: September 18, 2015; Published: November 29, 2015

*Corresponding author: Mette Geil Kollerup, Department of Nursing, Aalborg Municipality, Gravlevvej 21, 9520 Skørping, Denmark, Tel: +045274-44001; E-mail: mgk@rn.dk

\begin{abstract}
Background: Despite research on caring for older persons' basic needs, a number of hospital admissions occur which had been preventable, given the proper attention to caring for the basic needs. Literature show that caring for the basic needs of frail older persons can be complicated if they are suffering from chronic diseases and complex functional impairments. A starting point for an exploration of this complexity is the identification of frail older persons' basic needs
\end{abstract}

Aim: To explore the challenges in nursing assessment of basic needs when the older persons' frailty also implies impressive and expressive difficulties.

Method: We used Spradley's theory of participant observation. Data were collected from three older persons' individual assessment meeting, followed by individual interviews with the nurse. Field notes and transcribed dialogues from the assessment meetings and interviews were analyzed systematically in four steps.

Findings: Very limited input from the frail older persons characterizes the assessment. The nurses gave ample time and listened patiently to the older persons' voices to understand his or her limited verbal and nonverbal expressions. Using different types of questions, answers, body language and interpretations the nurses ensured that they had heard correctly and understood the older persons' remarks and answers. This revealed two themes: Patiently eliciting the older person's voice, and Empathic listening piecing fragments together to form an understanding.

Conclusion: When patient age and frailty implies impressive and expressive challenges, the nursing assessment of basic needs requires well developed nursing skills to create a facilitating setting that involves the frail older person. The nurse elicits patiently the older person's voice, and listens empathically to piece fragments together to form an understanding. Using imagination and improvisation trying out different solutions, the aesthetic nursing skills are seen prominent though related to the empiric-, ethic-, and personalskills. This enabled the nurses in enhancing the frail older persons participation and helped to maintain dignity despite impairment and limited input.

Keywords: Basic needs; Frail older persons; Health services for the aged; Community health nursing; Needs assessment; Nursing assessment; Nursing skills; Participant observation

\section{Introduction}

Caring for basic needs can be complicated if the older person who needs help is suffering from chronic illness and complex functional impairments. Despite numerous studies on caring for the basic needs of the older persons, a number of hospital admissions yet occur which had been preventable given proper attention to care of basic needs. In this paper, we explore the challenges associated with the nurse's assessment of the frail older person's basic needs and the skills it requires.

\section{Background}

There are many challenges involved in the process of ageing. Some daily activities like eating, personal hygiene and mobility can become so difficult that pressure sores, infections or fractures occur. These ailments remain a challenge in the care of frail older persons but can often be prevented. Studies report that the incidence of preventable conditions correlates with patient safety and the quality of the care. For instance, in a study on patient safety in the home, Wertenberger [1], reports that preventing falls, infections and medication errors will improve the patient safety for frail older persons. In addition, Saliba et al. [2], accentuate the assessment and management of malnutrition, pressure sores, in continence and mobility problems as important indicators of patient safety. The fact that $10 \%$ of hospital admissions are characterized as preventable is problematic [3]; therefore, in 2011 the Danish policymakers decided to focus on this specific problem [3]. The aim was to avoid admissions caused by bowel infections, cystitis, fractures, anaemia (caused by malnutrition), pressure sores, dehydration, lower respiratory tract disease, diabetes and constipation. According to statistics [4], the percentage of these preventable admissions increases with age, thus indicating a correlation between increasing age and challenges in caring for basic needs. The appropriate help needed for basic needs as eating, drinking and assisting with elimination can improve the prevention of anaemia, dehydration, diabetes or cystitis, bowel infections and constipation [5-12]. Other studies find that lower respiratory tract disease is linked with the basic need to breathe normally [13], and fractures, contractures, and pressure sores with the basic need for mobility and proper body mechanics [14-18]. 
Even though growing old is not synonymous with the need for professional care more studies indicates a correlation. For example, $90 \%$ of care home residents need help to manage at least 4 out of 5 daily life activities [19]. The care is further complicated by illness and weakening, and Shirm [20] found that $80 \%$ of care home residents suffer from 3-5 illnesses. This study of the health status of older persons in need of professional care was published in 1989. More recently, Hjaltadóttir et al. [21], found a lack of knowledge of newly admitted care home residents' care needs; and Worden et al. [22], pointed to increased care needs in nursing homes due to a growing number of older people living with chronic health conditions due to expanding treatment possibilities.

It is relatively uncomplicated for healthy, self-sufficient people to manage their own basic needs simply and easily. However, the literature concludes that when it comes to managing other persons' needs, and when these persons are older, frail and ill, the complexity increases [5,7-10,14,16,18,23-25]. This challenge was explored by Levine et al. [26], who found that it is not possible to treat older persons' chronic illnesses with traditional treatment regimens because of complex comorbidities, such as incontinence, immobility and malnutrition. A link between malnutrition and mental deterioration was also found by Mentes [7], in that $58 \%$ of the $30 \%$ dehydrated older persons in his study refused to drink. Levine's study [26] on the disease management of frail older persons supports the contention that the illnesses may often be further complicated by mental deterioration, complex social conditions and cooperative issues between the primary professional care givers in the patient's home that involve close relatives or other health professionals. Further, Levine et al. [26], point to a need for a new approach consisting of a combination of health professional expertise and individual care initiatives. They argue that the situation of each older person is unique, thus care must be arranged on an individual and professional basis. According to Lekan [27], the planning of the individual care of older persons should be based on the assessment of their basic needs and on the reasons for their functional losses. The core in the planning of the care is, therefore, to assess the health status, capabilities, values, and interests in the older person's daily life. The question remains how the actual needs themselves are identified. When assessing older persons' needs, their frailty is often an issue. Despite several studies on assessment of frailty in older persons [28-31], none studied the assessment of basic needs in frail older persons. Frailty addresses primarily functional decline as weight loss, exhaustion, weakness, slow walking speed and low levels of physical activity [28-30]. However, in the interaction of the assessment the mental part is central as well. This study concerns the particular situation of assessment of frail older persons' basic needs. The aim of this study is to explore the challenges in nursing assessment of basic needs when the older persons' frailty also implies impressive and expressive difficulties.

\section{Method}

In achieving detailed insight into the assessment process the ethnographic method has its force. Following Spradley's [32] theory of participant observation, it was possible to observe the dialogue and the actions and interactions among the participants at the assessment meetings. Subsequent interviews with the involved nurses provided the opportunity to reveal their reasoning and underlying knowledge related to the observations. Using this combination, we achieved a deeper insight into nursing assessment of frail older persons' basic needs than interviews or observations alone could have provided and discovered cultural behavior and cultural knowledge.

\section{Setting and Participants}

The basis of the study included three older persons' individual assessment meeting in connection with their need for professional care (one visit per person) in a Danish municipality. The meetings concerned assessment of the participants' basic needs and took place in their homes. The nurse's task was to determine the type and level of help to be granted by the municipal health professionals. The assessment was to identify the basis for the daily care of the older person's needs. Two experienced registered nurses and three older persons took part in the study (Table 1). By choosing experienced nurses (more than 10 working years) we hoped to see the most developed nursing skills. In selecting the older persons we asked for frail older persons with the aim to explore the most difficult situation of nursing assessment. The three participating older persons with impressive and expressive difficulties therefore represent the nurses' understanding of the concept "frail". The number of relatives and health care professionals from the municipality present varied and was not the focus of this study.

\section{Data Collection}

The participants in the assessment meetings were seated around a table in the older person's home before the nurse arrived. The data collector sat in the background and did not interact during the meeting, which Spradley terms passive observation [32]. Each meeting lasted an hour and was audio-taped to enable the data collector to focus on visual data like facial gestures and posture, and to make field notes on these observations during the meetings. After the first assessment meeting, the field notes became less descriptive and more focused on aspects identified as important [32], namely the interaction between the older person and the nurse, the pace of the conversation, and the participation of the older person. The observer conducted a 30-minute audiotaped interview with the nurse after each assessment meeting. The interview focused on the nurse's considerations of the incidents during the assessment that she or the observer found important.

The audio recordings of the assessment meetings and interviews were transcribed verbatim. The data totalled 71 pages of transcripts and field notes from $41 / 2$ hours of observations and interviews.

\section{Data analysis}

According to Spradley [32], analysis is a systematic investigation that aims at deciphering elements, finding associations between these elements and their association to the 


\begin{tabular}{|c|c|c|c|c|}
\hline Resident & Nurse & $\begin{array}{l}\text { Health status. } \\
\text { Information from health } \\
\text { care staff }\end{array}$ & $\begin{array}{l}\text { Language observed at } \\
\text { the visitation assessment } \\
\text { meeting }\end{array}$ & $\begin{array}{l}\text { Participants at the } \\
\text { assessment meeting }\end{array}$ \\
\hline $\begin{array}{l}\text { 87-year-old unmarried } \\
\text { woman. } \\
\text { Former teacher. }\end{array}$ & A & $\begin{array}{l}\text { Several apoplexies, } \\
\text { hemiparesis, osteoporosis }\end{array}$ & $\begin{array}{l}\text { Latency, whisper, quiet voice. } \\
7 \text { statements, up to } 6 \text { words } \\
\text { at a time }\end{array}$ & $\begin{array}{l}\text { Resident, sibling } 1,2,3 \text {, one } \\
\text { person from health care staff, } \\
\text { nurse }\end{array}$ \\
\hline $\begin{array}{l}\text { 80-year-old male. Former } \\
\text { occupation unknown. }\end{array}$ & B & $\begin{array}{l}\text { Apoplexy, paresis, expressive } \\
\text { aphasia }\end{array}$ & $\begin{array}{l}\text { Yes-no-converse, difficulties } \\
\text { expressing other words, } 42 \\
\text { statements up to } 7 \text { sounds at } \\
\text { a time }\end{array}$ & $\begin{array}{l}\text { Resident, spouse, daughter, one } \\
\text { person from health care staff, } \\
\text { occupational therapist, nurse }\end{array}$ \\
\hline $\begin{array}{l}\text { 71-year-old male. } \\
\text { Former engineer. }\end{array}$ & B & $\begin{array}{l}\text { Parkinson's disease, reduced } \\
\text { short-term memory }\end{array}$ & $\begin{array}{l}\text { Long incoherent flow of } \\
\text { speech, sounds, phrases and } \\
\text { associations, } 184 \text { statements } \\
\text { up to } 52 \text { words at a time }\end{array}$ & $\begin{array}{l}\text { Resident, spouse, one person } \\
\text { from health care staff, } \\
\text { physiotherapist, nurse }\end{array}$ \\
\hline
\end{tabular}

Table 2: Taxonomic analysis of the domain: The elderly person's language.

\begin{tabular}{|l|l|l|l|}
\hline \multirow{2}{*}{$\begin{array}{l}\text { The older person's } \\
\text { language }\end{array}$} & Verbal & Comprehendible & Whisper, Inaudible speech, Clear answer \\
\cline { 2 - 3 } & Incomprehendible & $\begin{array}{l}\text { Yes-no-confusion, Use of phrases, Incoherent flow of speech, Sounds, } \\
\text { Mumbling, Difficulties in expressing words }\end{array}$ \\
\cline { 2 - 4 } & Nonverbal & Pauses, Laughter, Laughter and tears, Sparkling eyes, Clasped hands, Twisting hands \\
\hline
\end{tabular}

whole. Spradley [32], notes that the greatest obstacle in doing participant observations is to put aside one's own previous experiences. We recognized this challenge in that the preliminary analyses were influenced by the routine structures of community nursing and well-known by the first author from her previous positions. Subsequently, learning from experience, the data analysis was improved following Spradley's [32] guidelines systematically in 4 steps. This ensured that routine structures and perceptions in the data were dismissed. In the first step, the domain analysis, the data were searched for words which could be grouped in different semantic relations suggested by Spradley, such as "being a part of", "contributing to" or "being somewhere in". For example, "mumbling", "whispering", "yes-no-confusion" are parts of the domain: "The older person's verbal language". We found 42 domains. In the second step, the taxonomic analysis, the domains were further explored by finding similarities and disparities and organizing the words into a hierarchy showing words and concepts' relation to each other (Table 2).

Each component of the taxonomic analysis was further investigated in the third step, the componential analysis, where attributes, causes and consequences of the components were sought. For example, in relation to each of the older person's verbal expressions, we asked questions such as, "Why is the older person mumbling", and, "How does the nurse react to the mumbling". This was the most detailed level of the analysis. The fourth and last step was the theme analysis, a total summation of the analyses based on different tasks, leading to a sense of the whole.

\section{Ethical Considerations}

The study was reported to and approved by the Danish Data Protection Agency. We followed its guidelines regarding information, consent, storage and destruction of the data [33]. The Helsinki Declaration [34] states that studies of frail older persons may only be undertaken if the same studies cannot be carried out on able persons. The point of our study was precisely that the participants had impressive and expressive difficulties in understanding and expressing their basic needs, hence the study was justifiable. Our main ethical concern, then was that taking part in the study did not inconvenience the older persons involved. Therefore, the head of the visitation office was constituted gatekeeper, and the nurses arranged the contact to the older persons to ensure that they could refuse to participate without feeling obliged to the first author. All of the participants received oral and written information adjusted to their situation, and they, or their relatives, signed an informed consent form.

\section{Findings}

We found that the assessment nurse made a strong effort to keep the older persons, who needed time and support, on track during the meeting. The setting itself, with all the stakeholders present, was a challenge in terms of capturing the perspectives of the older persons and meeting the needs of the other participants. The different perspectives meant that their interests were not always congruent. We found that the assessment nurse facilitated the older persons' voice. The older persons' needs were identified by giving them the necessary time to process their impressions and express themselves and by facilitating their voices. This revealed two themes: Patiently eliciting the olderly person's voice and Empathetic listening piecing fragments together to form an understanding.

\section{Patiently eliciting the older person's voice}

The older person's impressive and expressive difficulties meant that nurse had to listen carefully. The expressive difficulties could be latency, whispering inaudible speech, yes and no answers or even confusion between yes or no or long incoherent statements. Reduced mobility from paresis 
or stiffness, plus unprovoked laughter, with or without tears, had an impact on the nonverbal language. Mental impairment was evidenced by fleeting eyes, distractions that hindered eye contact when addressed, and lack of speech. An example was when a feeble whisper from the older person was heard three quarters of the way into lively and, at times, noisy exchanges between the participant's relatives and the nurse about her need for an ear specialist: "(mumbling noises)... No... (silence), no, it's no problem". Before this point in the conversation the older person had not said anything, despite several direct questions and invitations from the nurse. Everyone seemed surprised, dialogue stopped and the tempo of the conversation slowed down remarkably. Another example occurred when the nurse asked the participant a direct question; after a long pause of 11 seconds, a barely audible answer came. In the following interview the nurse emphasized the importance of the older person being given ample breathing room: "It is very revealing, when you get something from her, when you realize that she is quite capable of answering - and how much breathing room she needs to be able to do it". Thus, the challenge of facilitating the older person's voice required a great deal of patience and addressing the person continually, even though he or she did not seem to be able to contribute.

\section{Empathic listening piecing fragments together to form an understanding}

During the assessment meetings, it was a hindrance that the frail older persons were so challenged in communicating their own needs and desires. This made it rather difficult to uncover the person's need for help with basic needs, leaving the nurse to piece together speech, facial expressions, gestures, body language, and stories from the older person's past to hear and understand what was said.

Often the relatives or the staff answered on behalf of the older person, and then the nurse sought confirmation from the older person with an ascertaining question like, "You can walk a little?" or by elaborating or clarifying the question. These questions concerned meals, hygiene, elimination, dressing, sleep and rest, social contact and activity; questions that dealt with the older person's capacities: "Can you manage to eat by yourself", "Do you have your meals alone or with others?", "Can you dress yourself?" and the like.

Sometimes the nurse addressed the older person directly and asked close-ended questions. When the nurse asked an open-ended question, it was quickly followed by a close-ended question. The nurse explained this by saying: "We are trying to find something that he can relate to". The nurse was conscious of asking simple questions and helping the participant to answer, and explained: "It must be something he can answer either yes or no to". The answers brought different topics into the conversation. One older person had a lot he wanted to say, but could not structure the message and deliver it clearly. For instance, when the nurse asked whether he slept at night, he answered: "yes, aahh.... I..... (pause) ..... it is interrupted, though, I keep up with everything ... it is part of it ..... Something from others ....it makes .....I get a little frightened ... it aahhh ... and ..... I can't hear ..... I think it is right .... the last ... they are smashing ..". The nurse listened to these answers without interrupting, and then replied by summing up the main point to check that she had correctly understood him.

When the older person uttered words, made sounds or movements, the nurse responded by repeating the words, confirming the answer and by elaborating or interpreting the statement or movement. She was attentive to the fact that the participant's answers could not always be taken at face value. In such cases, the nurse put follow-up questions to the older person or the others present. After a dialogue with the others present, she sought verbal or non-verbal confirmation from the participant by repeating what the others had said. The nurse paid attention to points of value for the older person or the relatives. These could concern special interests or former occupations, meaning that a conversation would segue from drives in the countryside, to delivery of medicine, to hanging up lamps and curtains, to the view from the flat window, in short everything concerning the older person's basic needs.

The nurse also used the past life of the older persons as a context for understanding their incomplete utterings. In the conversations, the nurse made references to the participants' former occupation, family or interests. A nurse remarked during the post-assessment interview: "This was extremely helpful to the staff". Another related: "Her (the participant's) eyes sparkled when her school was mentioned - and the area surrounding it she had probably had a lot of good times with the pupils there". This was an example of the nurse interpreting the older person's nonverbal speech in a conversation where the subject had said very little, and it demonstrated that the nurse saw the value of including the person's past history in the assessment. Another example was a former engineer who had brought paper and pen to the meeting. The nurse said: "it meant a lot to him that he still had standing that he was someone once.., dates and numbers were once his 'thing'". Thus, the nurse had a professional motive or aim for her interest in the older person's past.

The nurse's interpretation of body language was a salient feature in all the conversations at the assessment meetings. In the post-assessment interview, the nurse was conscious of what she had observed, saying: "There were tears in his eyes when he laughed, but this could be due to his condition". During the assessment meetings, the nurse used her body language: She sat beside the subject, turning to face the person, had eye contact and employed touching. The nurse also used her body language to support the dialogue by gesticulating. For instance, during a conversation about whether the participant liked walking outdoors, she grasped his arm to demonstrate that it was sunburnt, to proof that he had been outdoors. The postassessment interview confirmed that the nurse could recall her use of body language. Thus, the nurse had both provided an open platform for the older person's voice and benefitted from the relatives' knowledge of the person. The former required the constant stimulation and awareness of the participants' attempts to express themselves by means of addressing them, using eye 
contact, touching, asking questions the older persons could relate to, drawing on knowledge of their earlier lives, listening to every utterance, searching for interpretations of body language and confirming these interpretations in various ways.

\section{Discussion}

By studying how the nurse listens to the older person's voice and pieces together different kinds of expressions and impressions to hear and understand what the older person says, we reveal the specific skills required of the nurse in an assessment. The older person needed time and support to express himself. The nurse maintained focus on the older person's perspective, and this was a challenge with all the important stakeholders present. Ideally, the stakeholders' knowledge of the older person should ensure making the best decisions, however, due to the older person's frailty, they could easily dominate the meeting. Still, it was the nurse's responsibility to ensure that the decisions made were in line with the older person's preferences. To facilitate this, the subject had a central place at the meeting table and had the nurse's attention during the entire meeting--also when she spoke to the other participants. When the nurse managed to uncover the frail older persons' basic needs, it was by encouraging them to speak for themselves. The intentions of the older persons were sought in the interpretation of their utterances, facial expressions and gestures. A speech impairment required the nurse to be sensitive to and reflect on different kinds of expressions and thereafter make her decision on this basis. To ensure that decisions were made in line with the older persons' own wishes and needs, it was sometimes necessary for the nurse to improvise and use her own imagination.

The use of improvisation, imagination and trying out different solutions was seen in the nurses' sense of using language in various ways, of touching or not touching the subject and the ability to imagine different solutions and to find meaning in the (sometimes) incoherent statements of the older person. These may be components of aesthetic nursing skills as described in the theory of patterns of knowledge in nursing. This theory is based on Carper's [35] findings that nursing theories over the last 100 years include the same four types of knowledge: empirical- ethical-personal- and aesthetic- knowledge. The aesthetic nursing skills were considered the most prominent, this notwithstanding the importance of empirical-, ethicaland personal- nursing skills. The nurse drew on her empirical knowledge [36] in relation to the older person's illness when she interpreted the person's incoherent statements due to illness, and deduced how the illness affected the person's behavior. Aesthetic knowledge is firmly joined to personal- and ethical-knowledge, which were evidenced by the nurse's genuine interest in own and others' personal selves, and a sincere effort to understand the older person, who had an impairment, in expressing own wishes and needs. When the nurse was aware of her and the other participants, and met the older person openly and with the aim of a meaningful interaction, she achieved a sense of the older person's values and interests. When the nurse succeeded in eliciting the frail older person's voice and piecing together an understanding, it was the result of her empathy and professional concerns about doing well in the situation [36]. These ethical considerations help to safeguard basic human values like dignity and respect [36].

When interviewing frail older persons with speech impairments, maintaining their dignity is as important for the nursing ethics as it is for the nurse to get useful answers. The starting point is how to get into a dialogue with the participant to get information and ensure agreement. In clinical practice the situation of the older persons is the actual goal of the conversations, whereas in research interviews it is to obtain knowledge that is not directly advantageous for them. Kirkevold \& Bergland [37], studied the frail older person's participation in qualitative interviews.

Although the target of their study was older persons as informants in qualitative interviews, they uncovered challenges converging with those in clinical practice. Ethical skills are significant in interviewing both in research and in nursing practice. We found that interviewing the older persons required time, patience and a specific effort in relation to interpreting their answers. These are elements we also noted in Kirkevold \& Bergland's study (37). In our study the subjects had sensory problems, problems concentrating, memory lapses and language difficulties, like aphasia. According to Kirkevold \& Bergland [37], these conditions can lead to the feeling of powerlessness. At the assessment meeting, this feeling can easily be exacerbated because the topic of discussion is precisely the older persons' capabilities. Thus, it was a challenge not to put on display the participant's functional incapacities. This was done, for example, by seating the older persons to a central position at the table before the conversation started, rendering their reduced mobility unnoticeable, in line with Kirkevold \& Bergland's [37] recommendations.

Further, the nurse's efforts to pose questions that the older persons were able to answer, was a way to avoid their feeling of powerlessness and provided a basis for them to experience some degree of control. The effort the nurse made to address the subjects and understand what they were saying showed them her respect.

Delving into the older persons' earlier life was another initiative the nurse used to engage with the subjects. Episodes from a person's past life can, according to Kirkevold \& Bergland [37], illustrate values and essential life quality and contribute to the older person being seen as more than a frail and dependent person, thus enhancing the dignity of the individual. Lastly, bringing into the conversation the person's past life helps to augment their participation and stimulates the interpretation of the older person's preferences.

This study describes how the nurse in the assessment of the older person's basic needs enables the patient's participation. Inclusion of the older person and placing him or her in a central position was an aim of the assessment meeting, according to the Ministry of Social Affairs, [38]. Our study showed that this could be done by physically situating the older person in a central position at the table. However, this study also shows that 
professional skills are required when an older person's weakened condition reduces his or her ability to participate. Angel's study [39] of patient participation underlines the importance of taking a starting point in the patient's perspective of the situation. When persons are physically or mentally debilitated, nursing typically entails doing what they would have done for themselves had they the ability and will [39]. When the older person lacks the ability to participate, the nurse's expectations towards participation may create further pressure in a difficult situation. If third parties should carry out decisions and actions, they must be in accordance with the persons' wishes. Thus, the nurse needs knowledge about the older person's values, interests and prior lives, which is precisely what we found the nurses attempting to do. Angel's study also showed that it was important for individuals' well-being to be able to participate to the extent that their ability and strength allowed [39]. Albeit difficult to quantify, ability and strength differing from individual to individual, the task lays strong claims on professionals. Not least because Angel [39], pointed out that the patient can only participate to the extent that the professionals allow. This encouragement was obvious in our study, in that the nurse created a platform where the older person could be heard. At the same time, it was also clear that no pressure was put on the subjects, and so the nurse gave them, as Angel [39] recommends, a chance to take part to the extent of their abilities and strength.

\section{Limitations of the Study}

Three social situations like we studied are what Spradley calls micro-ethnography (32, p. 29). He argues that "the concern with the particular is incidental to an understanding of the general" [32]. Thus by studying and communicating these particular situations we are able to "show" details and thereby spell out nuances that otherwise would be lost. We strived to show nuances in the assessment by outlining examples from dialogues in three particular assessment meetings. This provides more understanding of the skills needed to identify basic needs. However, the nurses' assessment is not practiced in isolation but is a part of the daily continuous assessment from stakeholders in the home, such as family and other health professionals. The older persons' basic needs are changing and so are the care plans. We have chosen to explore the nurses' assessment at the assessment meeting, not because it can stand alone, but because it is a situation where "concentrated" needs assessment occurs. We acknowledge that other health care professionals and relatives play an important role in the daily care of frail older persons.

\section{Conclusion}

Using imagination, improvisation and trying out different solutions, the nurses' aesthetic skills were prominent in assessing the frail older person's basic needs. Wondering why older persons are still getting admitted to hospital due to preventable ailments, this study draws attention to the complexity of assessing the frail older persons' basic needs, especially when suffering from impressive and/or expressive impairment. Taking into account that the explored nursing assessment only is a tiny part of the continuous daily assessment, this appears to be very fundamental. Further it points to the importance of continuous development of nursing skills.

\section{Acknowledgement}

The authors certify that there is no conflict of interest with any financial/research/academic organization, with regards to the research work discussed in the manuscript.

\section{References}

1. Wertenberger S, Wilson J. The development of a patient safety program across the continuum of care. Nurs Adm Q. 2005;29(4):303-7.

2. Saliba D, Solomon D, Rubenstein L, Young R, Schnelle J, Roth C, et al. Feasibility of quality indicators for the management of geriatric syndromes in Nursing Home residents. J Am Med Dir Assoc. 2004;5(5):310-9.

3. Vejledning Plejebolig. Reduktion af forebyggelige indlæggelser (Instructions for residental care facilities. Reduction of preventable admissions) [Internet]. 2012. Available from: http://www.kl.dk/ ImageVault/Images/id_48589/scope_0/ImageVaultHandler.aspx.

4. Sundhedsdata, Behandling ved sygehus, sygehusaktivitet på diagnoseniveau (Social conditions health and justice/hospitalizations/ hospitalpatients by region, diagnosis, age and sex) [Internet]. 2012. Available from: http://www.statistikbanken.dk/statbank5a/default. asp? $\mathrm{w}=1280$.

5. Cowan DT, Roberts JD, Fitzpatrick JM, While AE, Baldwin J. Nutritional status of older people in long term care settings: Current status and future directions. Int J Nurs Stud. 2004;41(3):225-37.

6. Damkaer K, Beck AM. Nursing home residents are still suffering of remarkable underweight. Sygeplejersken. 2007;107(9):34-8.

7. Mentes JC. A typology of oral hydration problems exhibited by frail nursing home residents. J Gerontol Nurs. 2006;32(1):13-9.

8. Schnelle JF, Simmons SF, Beuscher L, Peterson EN, Habermann R, Leung F. Prevalence of constipation symptoms in fecally incontinent nursing home residents. J Am Geriatr Soc. 2009;57(4):647-52. doi: 10.1111/j.1532-5415.2009.02215.x.

9. Wikby K, Fägerskiöld A. The willingness to eat: an investigation of appetite among elderly people. Scand J Caring Sci. 2004;18(2):120-7.

10.Wikby K, Ek AC, Christensson L. Implementation of a nutritional programme in elderly people admitted to resident homes. Scand J Caring Sci. 2009;23(3):421-30. doi: 10.1111/j.14716712.2008.00632.x.

11. Wissing $U$, Unosson $M$. The relationship between nutritional status and physical activity, ulcer history and ulcer-related problems in patients with leg and foot ulcers. Scand J Caring Sci. 1999;13(2):123-8.

12. Wisten A, Messner T. Fruit and fibre (Pajala porridge) in the prevention of constipation. Scand J Caring Sci. 2005;19(1):71-6.

13. Hecht A, Siple J, Deitz S, Williams P. Diagnosis and treatment of pneumonia in the nursing home. Nurse Pract. 1995;20(5):24, 27-8, 35-9.

14. Buss IC, Halfens RJ, Abu-Saad HH, Kok G. Pressure ulcer prevention in nursing homes: Views and beliefs of enrolled nurses and other health care workers. J Clin Nurs. 2004;13(6):668-76.

15. McGough-Csarny J, Kopac CA. Skin tears in institutionalized elderly: an epidemiological study. Ostomy Wound Manage. 1998;44(3A Suppl):14S-24S; discussion 25S. 
16. Theodos P. Fall prevention in frail elderly nursing home residents: a challenge to case management: part I. Lippincotts Case Manag. 2003;8(6):246-51.

17. Theodos P. Fall prevention in frail elderly nursing home residents: a challenge to case management: part II. Lippincotts Case Manag. 2004;9(1):32-44.

18. Wagner LM, Capezuti E, Brush BL, Clevenger C, Boltz M, Renz S. Contractures in Frail Nursing Home Residents. Geriatr Nurs 2008;29(4):259-66. doi: 10.1016/j.gerinurse.2007.09.002.

19. Ang YH, Au SY, Yap LK, Ee CH. Functional decline of the elderly in a nursing home. Singapore Med J. 2006;47(3):219-24.

20. Schirm V. Functionally impaired elderly: their need for home nursing care. J Community Health Nurs. 1989;6(4):199-207.

21.Hjaltadóttir I, Hallberg IR, Ekwall AK, Nyberg P. Health status and functional profile at admission of nursing home residents in Iceland over 11-year period. Int J Older People Nurs. 2012;7(3):177-87. doi: 10.1111/j.1748-3743.2011.00287.x.

22. Worden A, Challis D, Hancock G, Woods R, Orrell M. Identifying need in care homes for people with dementia: the relationship between two standard assessment tools. Aging Ment Health. 2008;12(6):719-28. doi: $10.1080 / 13607860802154382$.

23. Borrie MJ, Campbell K, Arcese ZA, Bray J, Hart P, Labate T, et al. Urinary retention in patients in a geriatric rehabilitation unit: prevalence, risk factors, and validity of bladder scan evaluation. Rehabil Nurs. 2001;26(5):187-91.

24. Brown S, Nay R. Urinary tract infection: under treated and investigated: an examination of the nursing management of urinary tract infections in nursing home residents experiencing impaired cognition. Int J Older People Nurs. 2007;2(1):20-4. doi: 10.1111/j.17483743.2007.00049.x.

25. Tingström P, Milberg A, Sund-Levander M. Early nonspecific signs and symptoms of infection in institutionalized elderly persons: perceptions of nursing assistants. Scand J Caring Sci. 2010;24(1):24 31. doi: 10.1111/j.1471-6712.2008.00680.x.

26. Levine S, Reyes JY, Schwartz R, Schmidt D, Schwab T, Leung M. Disease management of the frail elderly population. Disease Management and Health Outcomes. 2006;14(4):235-43.

27. Lekan D. Frailty and other emerging concepts in care of the aged

\section{SOUTH ONLINE J NURS RES. 2009;9(3):15p}

28. Saliba D, Elliott M, Rubenstein LZ, Solomon DH, Young RT, Kamberg CJ, et al. The Vulnerable Elders Survey: a tool for identifying vulnerable older people in the community. J Am Geriatr Soc. 2001;49(12):1691-9.

29. Searle SD, Mitnitski A, Gahbauer EA, Gill TM, Rockwood K. A standard procedure for creating a frailty index. BMC Geriatr. 2008;8:24. doi: 10.1186/1471-2318-8-24.

30. Rockwood K, Abeysundera MJ, Mitnitski A. How should we grade frailty in nursing home patients? J Am Med Dir Assoc. 2007;8(9):595603.

31. Markle-Reid M, Browne G. Conceptualizations of frailty in relation to older adults. J Adv Nurs. 2003;44(1):58-68.

32. Spradley JP. Participant observation. 10. printing ed. New York: Holt Rinehart and Winston. 1980.

33. Standardvilkår for forskningsprojekter <br />Anmeldelse af privat forskning (Standardprocedures for research, reporting of privat research) [Internet]. Datatilsynet; 2012. Available from: http:// www.datatilsynet.dk/erhverv/forskere-og-medicinalfirmaer/ standardvilkaar-for-forskningsprojekter/ http://www.datatilsynet. $\mathrm{dk} /$ erhverv/forskere-og-medicinalfirmaer/private-forsknings-ogstatistikprojekter/.

34. Helsinki declaration [Internet]. 2012. Available from: http://www. wma.net/en/30publications/10policies/b3/17c.pdf.

35. Carper BA. Practice oriented theory. Fundamental patterns of knowing in nursing... part 1 (2). ANS. 1978 10;1(1):13-24.

36. Chinn PL, Kramer MK. Development of knowledge in nursing. 1. udgave ed. Kbh.: Akademisk; 2005.

37. Kirkevold M, Bergland A. The quality of qualitative data: Issues to consider when interviewing participants who have difficulties providing detailed accounts of their experiences. International Journal of Qualitative Studies on Health and Well-being. 2007;2(2).

38. Service Agency (National board of health and welfare). Good case management for the elderly: methodological manual. Odense: Service Agency;2007.

39. Angel S. Patient participation during rehabilitation after spinal cord injury. Tidsskrift for sygeplejeforskning. 2010;26(1):20-5. 